\title{
Impacts of the Two Biggest Lakes on Local Temperature and Precipitation in the Yellow River Source Region of the Tibetan Plateau
}

\author{
Lijuan Wen, ${ }^{1,2}$ Shihua Lv, ${ }^{1}$ Zhaoguo Li, ${ }^{1}$ Lin Zhao, ${ }^{1}$ and Nidhi Nagabhatla ${ }^{2,3}$ \\ ${ }^{1}$ Key Laboratory of Land Surface Process and Climate Change in Cold and Arid Regions, \\ Cold and Arid Regions Environmental and Engineering Research Institute, Chinese Academy of Sciences, Lanzhou 730000, China \\ ${ }^{2}$ Asia-Pacific Economic Cooperation (APEC) Climate Center, Busan 612020, Republic of Korea \\ ${ }^{3}$ United Nations University-Institute for Water, Environment and Health (UNU-INWEH), 175 Longwood South, Hamilton, \\ ON, Canada L8P 0A1
}

Correspondence should be addressed to Lijuan Wen; gamevictory@gmail.com

Received 4 July 2014; Accepted 9 October 2014

Academic Editor: Francisco J. Tapiador

Copyright (C) 2015 Lijuan Wen et al. This is an open access article distributed under the Creative Commons Attribution License, which permits unrestricted use, distribution, and reproduction in any medium, provided the original work is properly cited.

The Tibetan Plateau harbors thousands of lakes; however few studies focus on impacts of lakes on local climate in the region. To investigate and quantify impacts of the two biggest lakes (Ngoring Lake and Gyaring Lake) of the Yellow River source region in the Tibetan Plateau on local climate, two simulations (with and without the two large lakes) from May 2010 to July 2011 are performed and analyzed using the WRF-CLM model (the weather research and forecasting model coupled with the community land model). Differences between simulated results show that the WRF-CLM model could provide realistic reproduction of surface observations and has better simulation after considering lakes. Lakes mostly reduce the maximum temperature all year round and increase the minimum temperature except in March due to the large heat capacity that makes lakes absorb (release) more energy for the same temperature change compared to land. Lakes increase precipitation over the lake area and in the nearby region, mostly during $02-14$ BT (Beijing Time) of July to October when the warm lake surface induces the low level horizontal convergence and updraft over lake and provides energy and vapor to benefit the development of the convection for precipitation.

\section{Introduction}

An army of researchers and scientists accept the observation and the outputs from simulations showing that lakes affect local climate significantly and the effects vary spatially and temporally [1-8]. Characteristics of energy budget over the lake surface are different. For example, research study from Lake Tanganyika in East Africa illustrates the annual mean heat loss increase by $13 \%$ and $18 \%$ by latent and sensible heat fluxes, resulting from the unstable atmosphere [9]. Contrastingly, the atmosphere during summer is usually stable for the North American Great Lakes [9]. Temperature response to the lakes also varies. For example, the surface temperature was $4^{\circ} \mathrm{C}$ less over the Great Slave Lake and the Great Bear Lake in Canada as compared to land in vicinity during July [10], while the simulation shows that the lake temperature is usually higher than that of land in southern Finland during all seasons [4]. Two large lakes on South-Central Baffin Island in Canada delay the seasonal cooling in fall and early winter for the interior lowlands under the influence of strong positive sensible heat fluxes [11]. The relative warming surface of lake can produce very obvious lake effect on precipitation, particularly for the downstream area [12-14]. Lake effect can increase up to 20$40 \%$ convective precipitation, during late summer and early autumn as shown from the case of Lake Ladoga in Russia [4]. Even the warmer lake surface may possibly lead to twofold increase in downstream winter precipitation over the Great Lakes region [15]. On the other hand, the Great Lake leads to $10-20 \%$ decline in precipitation during summer [16]. The above references elucidate that although the lake effect is apparent in different regions worldwide, the exact nature and gradient of the effect vary significantly. 


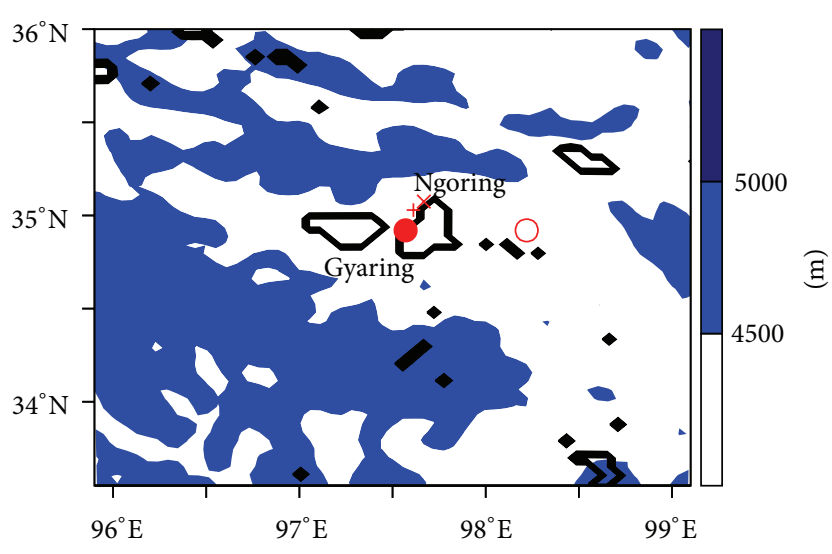

FIGURE 1: Terrain height (represented in meters and shown as shaded area) of the study area, the lakes (outlined by solid black line), and observation stations (Maduo station: hollow red circle; Border station: solid red circle; Island station: red plus; Grassland station: red cross).

In addition, lakes play an important role in the water cycle by providing significant surface water storage generated by precipitation, snow melting, and glacier melting [2, 17-19]. With recent global warming and scarcity of water resources, to explore lake effect on local climate is an important study towards the economic development planning for the landscape and for the societal benefit in terms of land use practices and livelihoods of communities around lake regions and related river basins.

The Tibetan Plateau harbors thousands of lakes on the highest altitude worldwide. The lake network covers nearly $44,993.3 \mathrm{~km}^{2}$ and covers about $49.4 \%$ of the total lake area in China [20]. The Tibetan Plateau is the source of major rivers in the region including the Ganges, the Mekong, the Yangtze, and the Yellow River. The Yellow River is the second longest river of China and fifth longest river in the world. The Yellow River source region is commonly referred to as the water tower of China [21] and occupies 48 lakes (area more than $0.5 \mathrm{~km}^{2}$ ). Lakes of the Yellow River source region are among the significant component of lakes network of the Tibetan Plateau. Ngoring Lake (Figure 1) is the biggest lake in the Yellow River source region. With the spread of about $610 \mathrm{~km}^{2}$ and an average depth of roughly $17 \mathrm{~m}$ (maximum depth is estimated as $30 \mathrm{~m}$ ), it ranges between its south and north (west and east) end nearly $30 \mathrm{~km}$. The second largest lake in the Yellow River source region is Gyaring Lake (Figure 1) with the spread of $520 \mathrm{~km}^{2}$. Two lakes are only about $20 \mathrm{~km}$ apart. They located $\left(97-98^{\circ} \mathrm{E}, 34.5-35.5^{\circ} \mathrm{N}\right)$ with an altitude more than $4,200 \mathrm{~m}$ in the semiarid region of the Tibetan Plateau.

Lakes spread of the Tibetan Plateau is known to influence local climate. In recent years, a few scholars have performed related research in the Tibetan Plateau with in situ observation, satellite data, and numerical simulation. The in situ observation data is scarce in the Tibetan Plateau because of its vast spread and remoteness, and in situ observation only reflects one-point information. Satellite data can provide very usefully spatial information, but it only reflects the information of transit time of satellite. Numerical simulation could provide spatial and temporal information with high resolution together and is chosen as the methodology of the study. So far, the numerical study on lake effect in the Tibetan Plateau mainly focused on its very short time effect on local climate [22]. In addition, there was few atmospheric model coupled with a lake model applied in the region. The lake surface temperature was only set as sea surface temperature from forcing data, which could not realistically represent the variation of lake temperature and interaction between air and lake. In order to fill the existing information gap, the present study will use the WRF-CLM model (the weather research and forecasting model coupled with the community land model) with ten-layer lake scheme [23] to study the relatively long term lake effect on local climate in the Tibetan Plateau. However, considering the limitation that the Tibetan Plateau is an extensively huge region and the "lakes" are a relatively smaller landscape scale, it is rather challenging for current computational clusters to perform a long term high resolution simulation for the entire Tibetan Plateau region. As a prototype to define the conceptual framework for the long term study of lake effect, the two biggest lakes (Ngoring Lake and Gyaring Lake) of the Yellow River source region in the Tibetan Plateau are taken up to do the study.

\section{Observation Data, Model, and Numerical Experiments}

2.1. Observation Data. The Tibetan Plateau has huge area, small population, and abominable natural conditions. The observation data in the Tibetan Plateau region is very scarce. In the simulated area, there is only one weather station maintained by China Meteorological Administration, called Maduo station $\left(98.2^{\circ} \mathrm{E}, 34.9^{\circ} \mathrm{N}\right)$ with $4,272 \mathrm{~m}$ altitude. Its observed daily $T_{2}$ (air temperature at $2 \mathrm{~m}$ height) and daily precipitation data available from China Meteorological Data Sharing Service System (http://cdc.cma.gov.cn/home.do) are employed to validate the model outcome during the temporal slice from July 1, 2010, to July 31, 2011.

To study lake effect on local climate in the Tibetan Plateau, we built 3 automatic meteorological stations at the border $\left(97.57^{\circ} \mathrm{E}, 34.92^{\circ} \mathrm{N}\right)$ of Ngoring Lake, over grassland $\left(97.65^{\circ} \mathrm{E}, 35.03^{\circ} \mathrm{N}\right)$ close to Ngoring Lake and in an island $\left(97.65^{\circ} \mathrm{E}, 35.02^{\circ} \mathrm{N}\right)$ in Ngoring Lake, respectively. These stations are referred to as Border, Grassland, and Island station in the following, respectively (Figure 1). At Border station, $T_{2}$ is collected since October 17, 2010, and used until the end of July in 2011. At Grassland and Island station, $T_{2}$ is also collected, but only in July 2010. LSST (The lake surface skin temperature) is also sampled from 12 to 27 of July 2010 at Island station.

2.2. Model and Numerical Experiments. The widely used and advanced regional atmospheric model, the WRF-CLM model, is employed to study the interaction between the atmosphere and the lake surface [23]. In the model, lake 
TABLE 1: Conditions of the simulation.

\begin{tabular}{lc}
\hline Simulated domain & Related condition \\
\hline Location of center & $97.5^{\circ} \mathrm{E}, 34.8^{\circ} \mathrm{N}$ \\
Horizontal grid spacing & $5 \mathrm{~km}$ \\
Horizontal dimension & $60 \times 60$ \\
Vertical atmosphere layers & 31 \\
Vertical soil (lake) layers & 10 \\
Lake depth & $17 \mathrm{~m}$ \\
\hline
\end{tabular}

TABLE 2: Parameterization schemes used in the simulation.

\begin{tabular}{|c|c|}
\hline Physics options & Parameterization schemes \\
\hline Microphysics & $\begin{array}{l}\text { Morrison double-moment } \\
\text { scheme [24] }\end{array}$ \\
\hline Shortwave radiation & Dudhia scheme [25] \\
\hline Cumulus parameterization & Kain-Fritsch scheme [26] \\
\hline Longwave radiation & $\begin{array}{l}\text { Rapid radiative transfer model } \\
\text { (RRTM) scheme [27] }\end{array}$ \\
\hline Land surface model & CLM 3.5 [28] \\
\hline Planetary boundary layer & $\begin{array}{l}\text { Yonsei University (YSU) scheme } \\
\text { [29] }\end{array}$ \\
\hline
\end{tabular}

processes and lake-atmosphere interactions are dynamically simulated using a $1 \mathrm{D}$ mass and energy balance lake scheme with 10 lake water layers [30]. The calculation of surface fluxes of lake is close to that of nonvegetated surfaces, which is used to calculate LSST. The calculation of each layer lake temperature is depending on the Crank-Nicholson thermal diffusion solution [30].

The domain of simulation is centered at $\left(97.5^{\circ} \mathrm{E}, 34.8^{\circ} \mathrm{N}\right)$ with $5 \mathrm{~km}$ horizontal grid spacing (Table 1). The horizontal dimension is $60 \times 60$. The vertical atmospheric layers are set to 31 . The vertical soil and lake layers are set to 10 . The lake depth is set as $17 \mathrm{~m}$ (a rough average depth of Ngoring Lake). The lake area can occupy 48 grids. The initial and the lateral boundary conditions are provided by the reanalyzed data Version II available from DOE/NCEP (the Department of Energy/National Centers for Environmental Prediction), where the lateral boundary data is updated every 6 hours [31]. The simulation with every 6-hour output is performed from May 2, 2010, up to July 31, 2011. The first 2-month simulation is discarded as spin-up. The selected physical options (Table 2) included Morrison double-moment scheme [32], Dudhia scheme [33], Kain-Fritsch scheme [24], rapid radiative transfer model (RRTM) scheme [25], CLM3.5 [26], and Yonsei University (YSU) scheme [27].

The aforementioned numerical experiment is called Slake (simulation with lake). In order to investigate and quantify the lake effect on local climate, another numerical experiment, S-nolake (simulation without lake), is performed for comparison with S-lake. S-nolake is based on S-lake, but the two big lakes (Ngoring Lake and Gyaring Lake) are filled with nearby land use cover (barren or sparsely vegetated), while the small lakes in the study area remain as such.

\section{Results}

3.1. Evaluation of the Simulations. Simulated results in S-lake are evaluated against observed daily $T_{2}$ at all four stations, precipitation at Maduo station, and LSST at Island station. Owing to the short term observation and the similar results, simulation at Island station and Grassland station is not shown in the figures and only their RMSE (root mean square error) is given in Table 3 . The magnitude and variations of simulated air temperature over lake and land in S-lake experiment are comparable with observations, but with a little cold bias in winter (Figures 2(a)-2(b)). The S-lake simulation captures the main precipitation events fairly well (Figure 2(c)) and the simulated daily precipitation agrees well with observation, except the simulation overestimates five precipitation events. The WRF-CLM model reproduces seasonal variability of precipitation with reasonable efficiency. It can be stated that the precipitation is of common occurrence (with $94 \%$ of the annual precipitation events happening in this time) during May to October, while during November to March, there is virtually no precipitation.

The S-nolake simulation is similar to S-lake (figure not shown here). But all RMSE between simulated variables and observations in S-lake is not bigger than that in Snolake (Table 3) and the S-lake has higher accuracy. In general, the WRF-CLM model can reproduce the variability of the observation well. The WRF-CLM model demonstrates relatively better simulation results over lake and its vicinity with the lake embedded compared with the experiment without lake.

\subsection{Lake Effect on Local Climate}

3.2.1. Lake Effect on $T_{2}$. The simulated annual average temperature in the region is relatively low as of the high altitude (Figure 3(a)). The simulated average annual temperature over the lake is noted as $-2^{\circ} \mathrm{C}$, while the value of the valley region surrounding the lake was noted as $-4^{\circ} \mathrm{C}$. The simulated temperature in the surrounding mountain area is simulated as $-6^{\circ} \mathrm{C}$ or even lower, and it further declines as the altitude escalates. Two broad points are derived from the simulation analysis. (1) The temperature distribution is notably influenced by the topography and the isotherm trend in the region overlaps with the terrain height contour. (2) The air temperature over lake and land shows similar seasonal and diurnal variations (Figures 2(a)-2(b)). The minimum (maximum) temperature about $-17(11)^{\circ} \mathrm{C}$ is simulated for January (July) and the simulated temperature is below $0^{\circ} \mathrm{C}$ from October to April (Figures 2(a)-2(b)).

The annual temperature difference between S-lake and $S$-nolake illustrates that the lakes are warmer than the land surface (Figure 4(a)). Figure 5(a) shows that the time series of monthly mean $T_{2}, T_{\max }$ (daily maximum $T_{2}$ ), and $T_{\text {min }}$ (daily minimum $T_{2}$ ) difference between S-lake and $\mathrm{S}$-nolake experiments averaged over the box $\left(96.7-98.4^{\circ} \mathrm{E}\right.$, $34.6-35.5^{\circ} \mathrm{N}$ ) in Figure 4. The enclosed area is represented by 651 grid squares in the model domain (about 15,000 $\mathrm{km}^{2}$ ) and more than 12 times the area of Ngoring Lake and Gyaring 


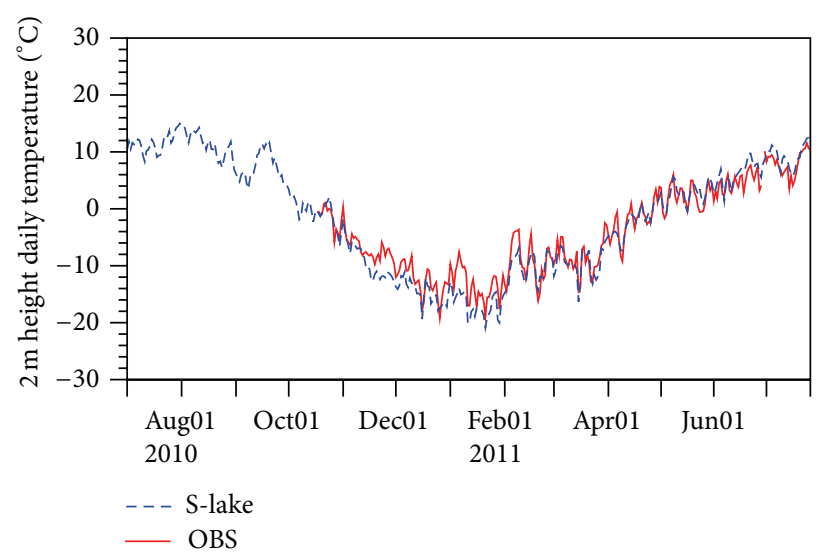

(a)

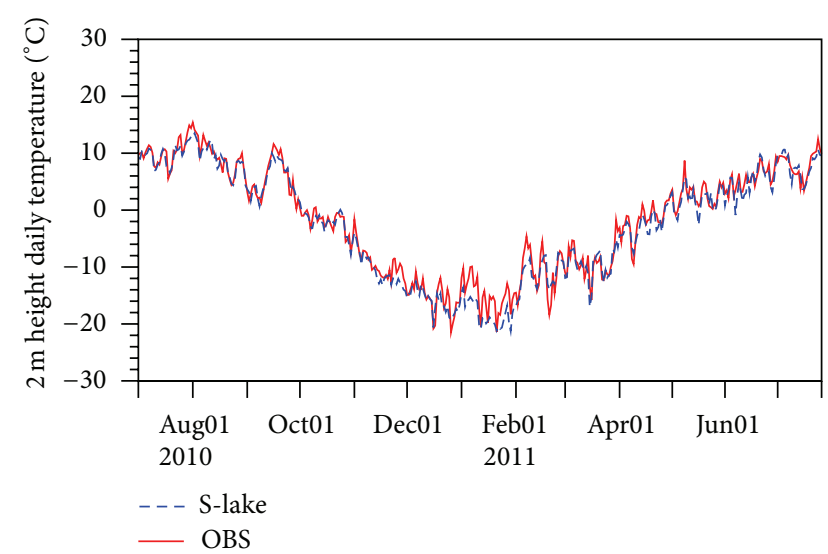

(b)

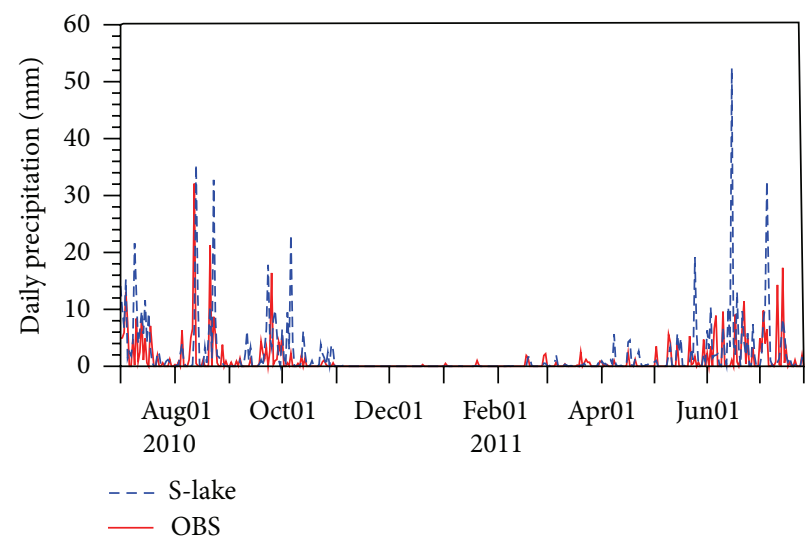

(c)

Figure 2: Observed and simulated daily temperature (a, b) and precipitation (c) at Border station (a) and Maduo station (b, c) in S-lake experiment.

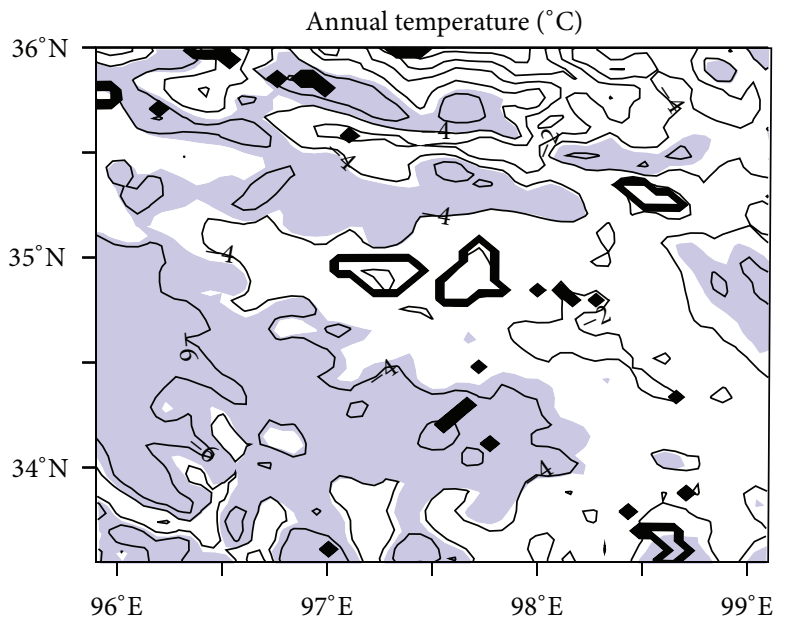

(a)

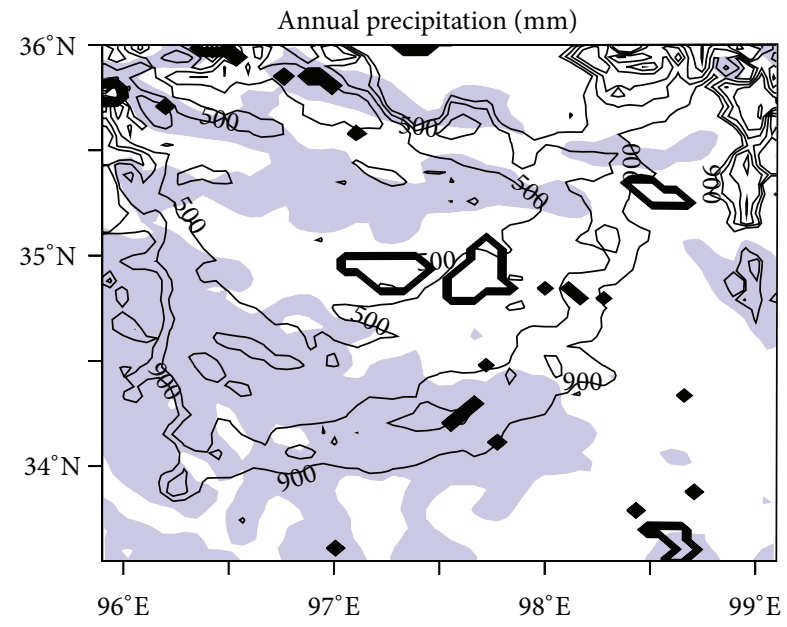

(b)

FIGURE 3: Simulated annually averaged temperature and annual precipitation (contours) from July 2010 to Jun 2011 in S-lake experiment. Shaded area indicates the area with above $4500 \mathrm{~m}$ terrain height. 
TABLE 3: RMSE of simulated daily precipitation $(\mathrm{mm})$ and temperature $\left({ }^{\circ} \mathrm{C}\right)$ at different stations.

\begin{tabular}{lcccccc}
\hline & $T_{2}$ at Maduo & Precipitation at Maduo & $T_{2}$ at Border & $T_{2}$ at Grassland & $T_{2}$ at Island & LSST at Island \\
\hline S-lake & 1.7 & 5.1 & 2.2 & 0.9 & 0.7 & 1.2 \\
S-nolake & 1.7 & 5.4 & 2.3 & 1.0 & 0.7 & 1.3 \\
\hline
\end{tabular}

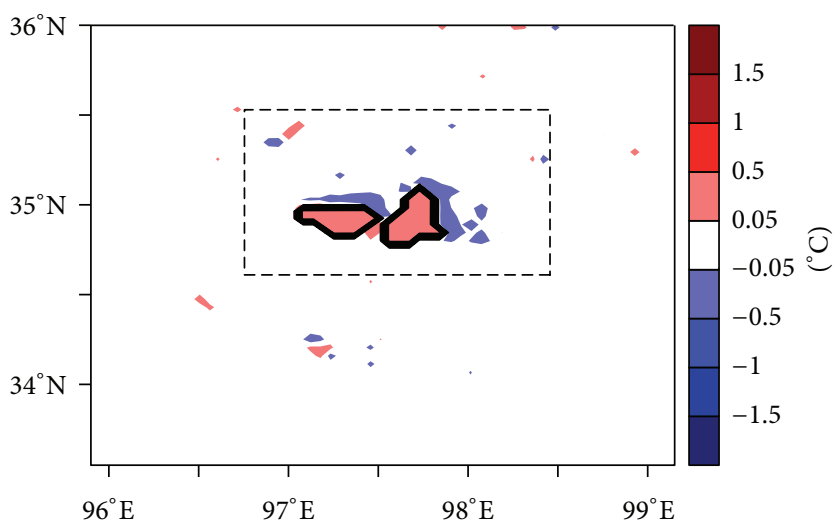

(a)

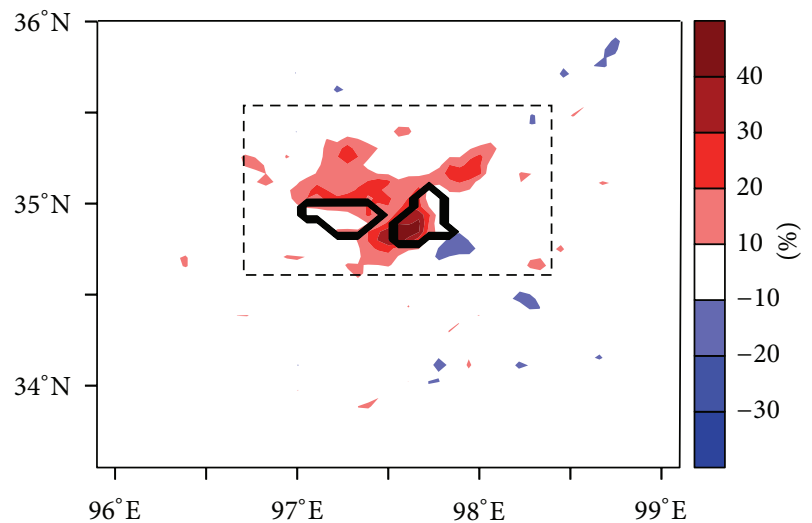

(b)

Figure 4: Annually averaged temperature difference (a) and annual precipitation difference (b) from July 2010 to Jun 2011 between S-lake and S-nolake.

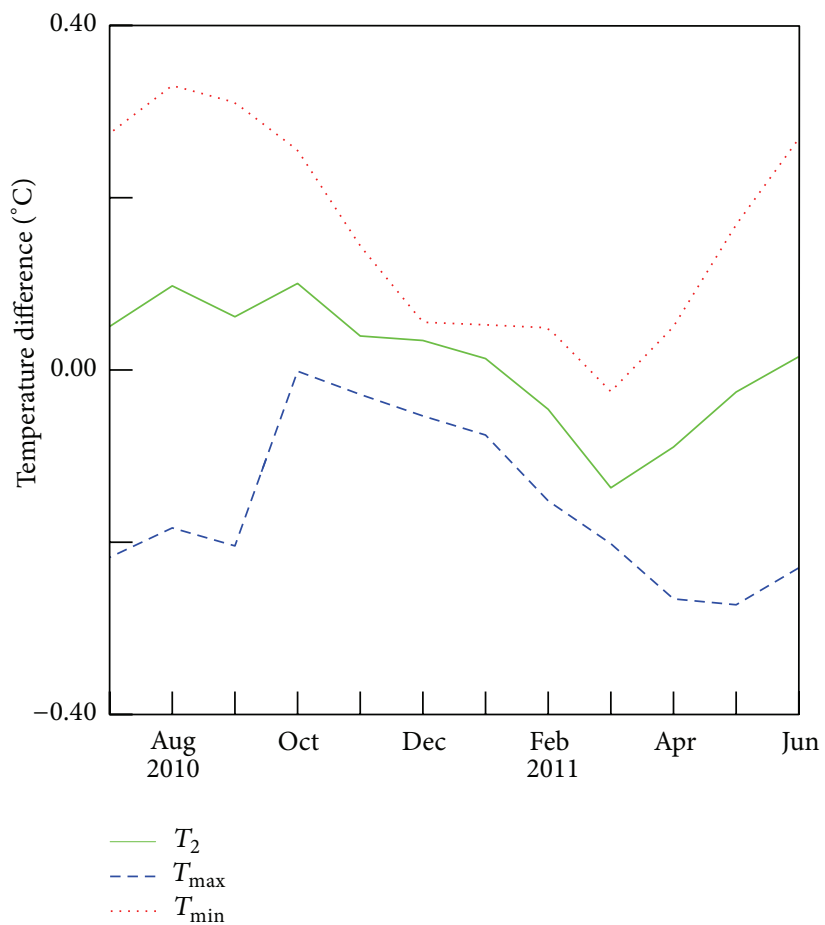

(a)

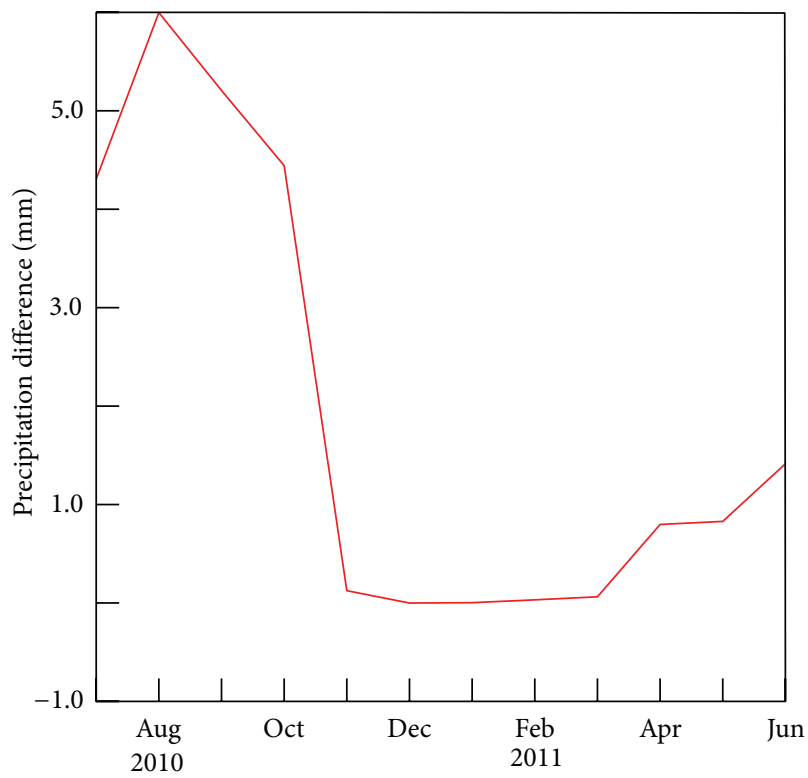

(b)

FIGURE 5: Area averaged monthly temperature difference (a) and precipitation difference (b) between S-lake and S-nolake.

Lake, which is represented by 48 grids in the model domain and about $1,200 \mathrm{~km}^{2}$. Lakes increase $T_{\min }$ throughout the year (Figure 5(a)), except March, while the lakes have no warm effects on $T_{\max }$ during the year. Averagely, the lake is warmer from June to January of next year (Figure 5(a)) and is acting as heat source, whilst it is cool from February to May. The growing season of native plants is from May to September. And the study area is fairly cold because of high altitude. The lake warming effect will benefit vegetation growth and ecosystem stability of the Tibetan Plateau region. 


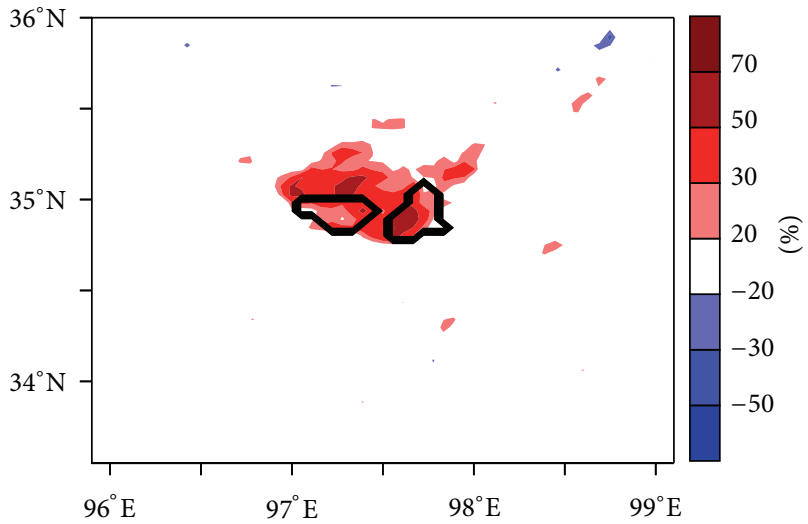

(a)

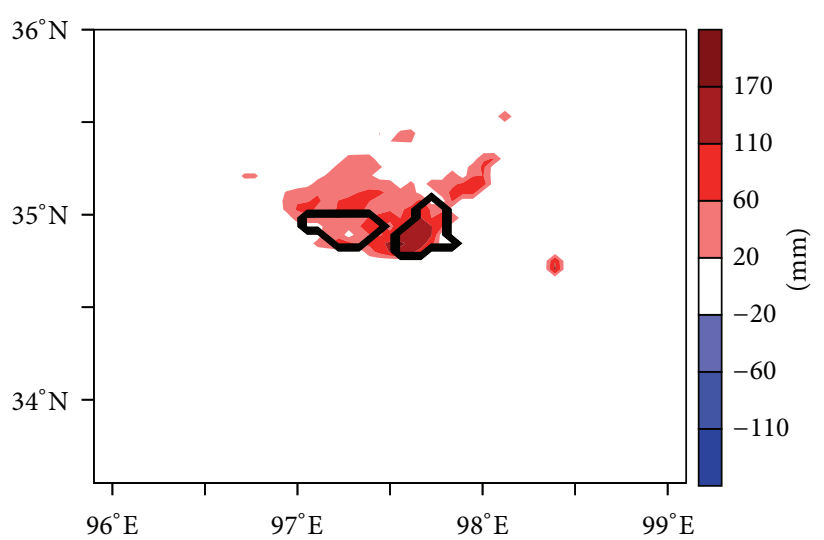

(b)

FiguRE 6: Precipitation difference ((a): percentage; (b): amount) between S-lake and S-nolake from July 2010 to October 2010.

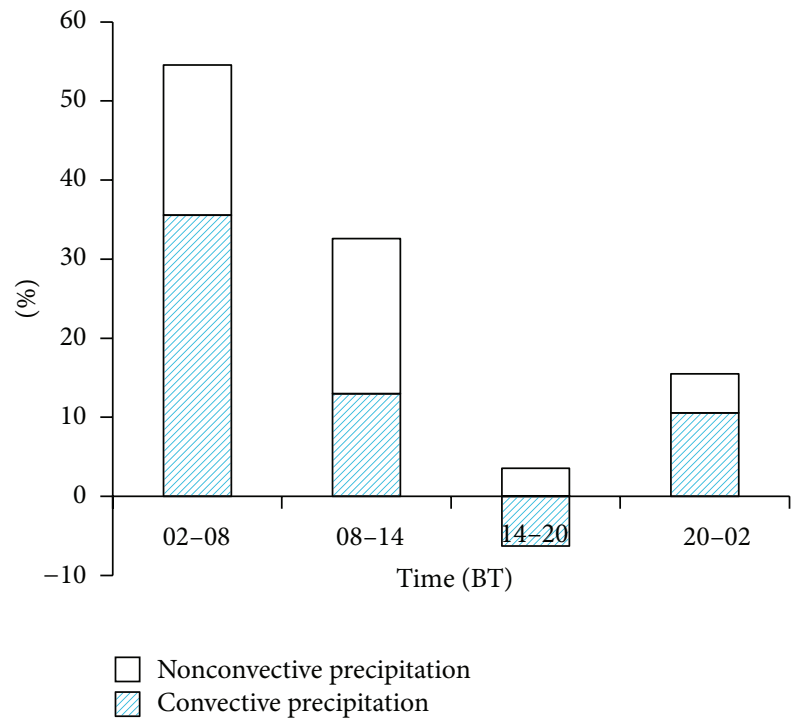

FIgURE 7: Percentage of precipitation difference between S-lake and $\mathrm{S}$-nolake to precipitation in S-lake at 4 different time periods from July to October 2010.

3.2.2. Lake Effect on Precipitation. Together with temperature, precipitation is influenced by the topography of the region (Figure 3(b)). The higher the elevation is, the higher the precipitation is. The gradient of the simulated precipitation fluctuates from less than $300 \mathrm{~mm}$ to more than $900 \mathrm{~mm}$ in correspondence to the lake area and its surrounding mountain area. The lake area has the least precipitation. 94\% precipitation occurs from May to October, while winter precipitation is negligible (Figure 2(c)). The simulated precipitation events occur at the same time in S-lake and Snolake experiments as observed from Maduo station. The precipitation is dominated by large scale circulation, while the lake alters its magnitude.
Annually, the lakes can increase up to $49 \%$ precipitation over lakes and their nearby area (Figure 4(b)). The influenced area with more than $10 \%$ increased annual precipitation occupies 158 grids (about $3,875 \mathrm{~km}^{2}$ ) over the lakes and their surroundings, more than 3 times the 48 lake grids. Most previous studies on such phenomenon have proven that the precipitation induced by lakes is of local significance and limited to the lake surface or closer to their surroundings $[2,16,28]$.

Figure 5(b) shows the monthly lake effect precipitation averaged over the box in Figure 4. The lake effect increases precipitation except the cold period when the time slice is not the rainfall season and has an overall very low to almost negligible precipitation (Figure 2(c)). Increased precipitation by Ngoring Lake and Gyaring Lake in spring and early summer is different with the study in the Great Lakes that leads to $10-20 \%$ decline in precipitation during summer [16]. The increase may be attributed to the high altitude, cold environment, and the high absorption of high solar radiation by the two lakes; thus the lake in the Tibetan Plateau easily maintains warm early (Figure 6(a)). The precipitation is significantly increased from July to October with the max in August. The increase in late summer and early autumn is similar to the boreal lakes in which Lake Ladoga in Russia could increase up to $20-40 \%$ convective precipitation [4]. Owing to the high altitude of the study area, lakes keep freezing with no rain in winter when the precipitation has no evident change. This is also different from the winter study in the Great Lake that is unfrozen and induces big lake effect precipitation in winter $[29,34]$.

$86 \%$ increased annual precipitation by lake effect happens from July to October which is mainly focused on hereafter. From July to October, Ngoring Lake and Gyaring Lake result in significant precipitation rise over lakes and the adjacent area (Figure 6). The increase can be up to $72 \%$, with most area recording $10-180 \mathrm{~mm}$ precipitation rise. The area with $20 \%$ increase in precipitation is nearly 151 grids (about $3,775 \mathrm{~km}^{2}$ ) amounting to 3 times the lake area. 


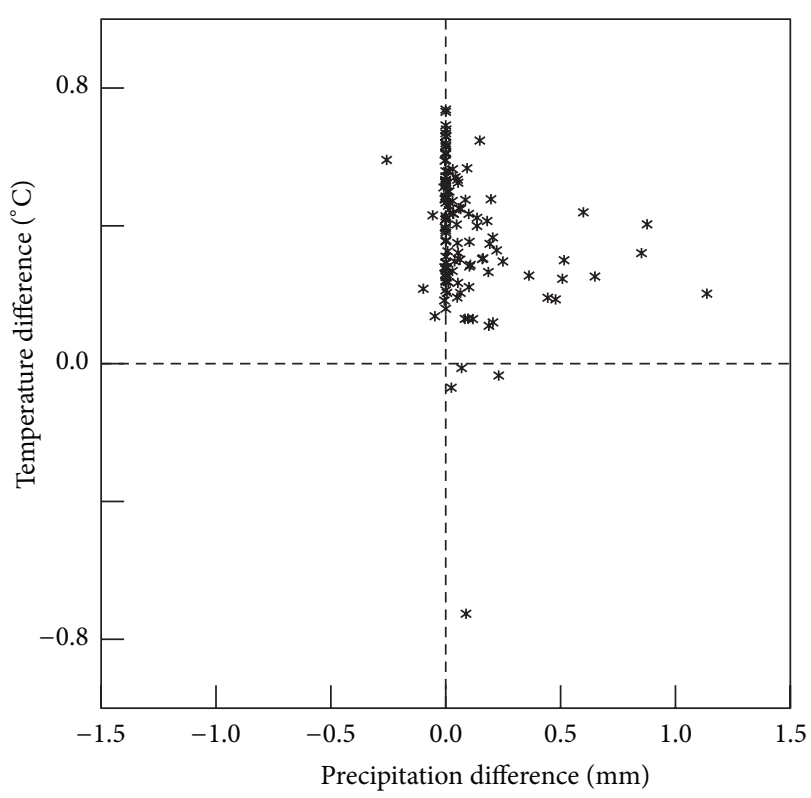

(a)

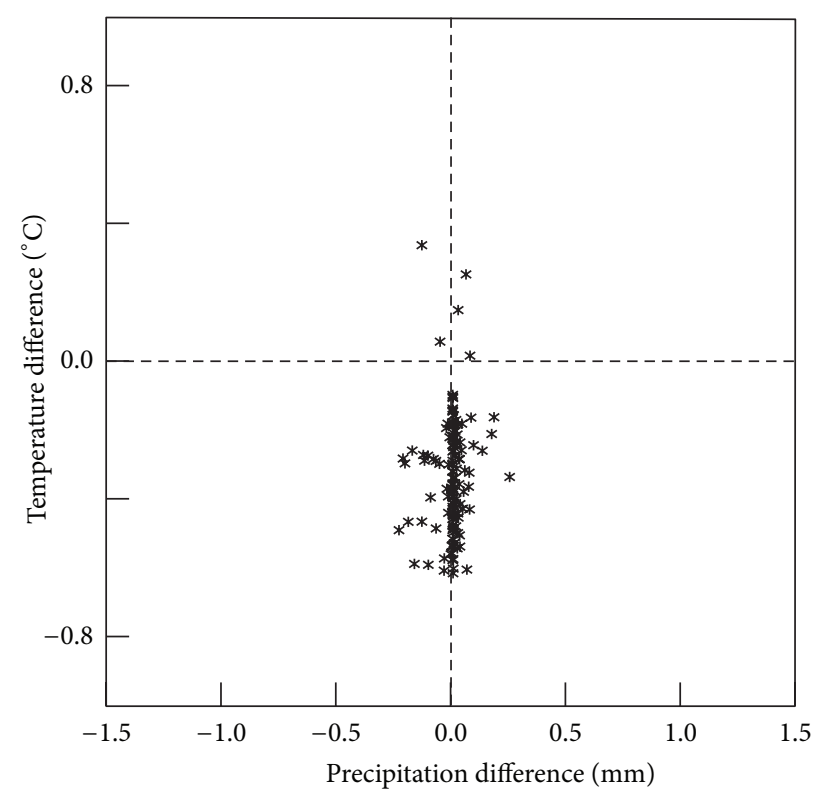

(c)

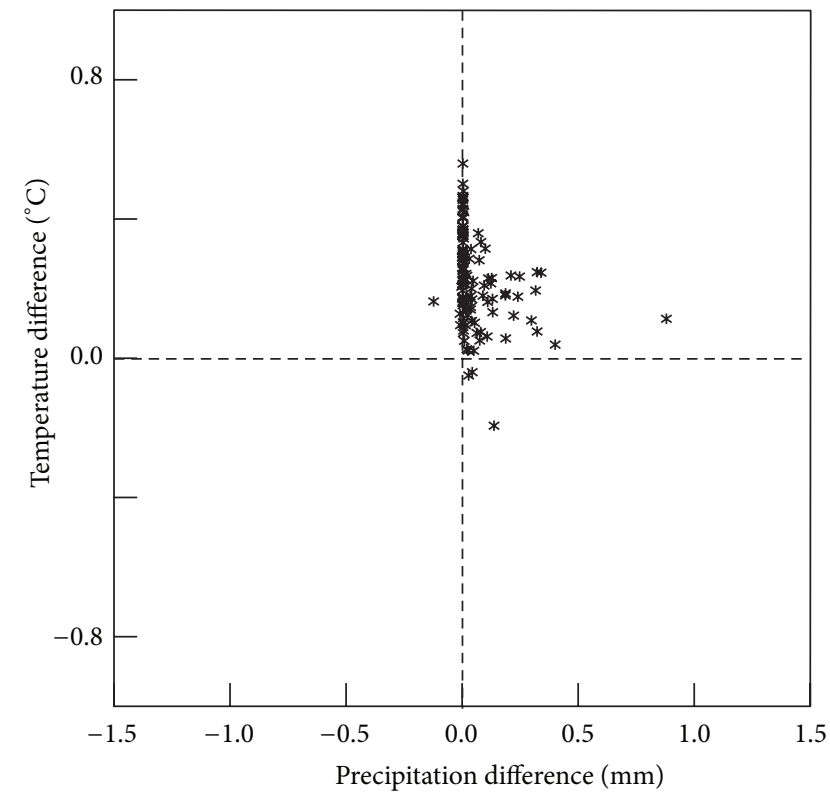

(b)

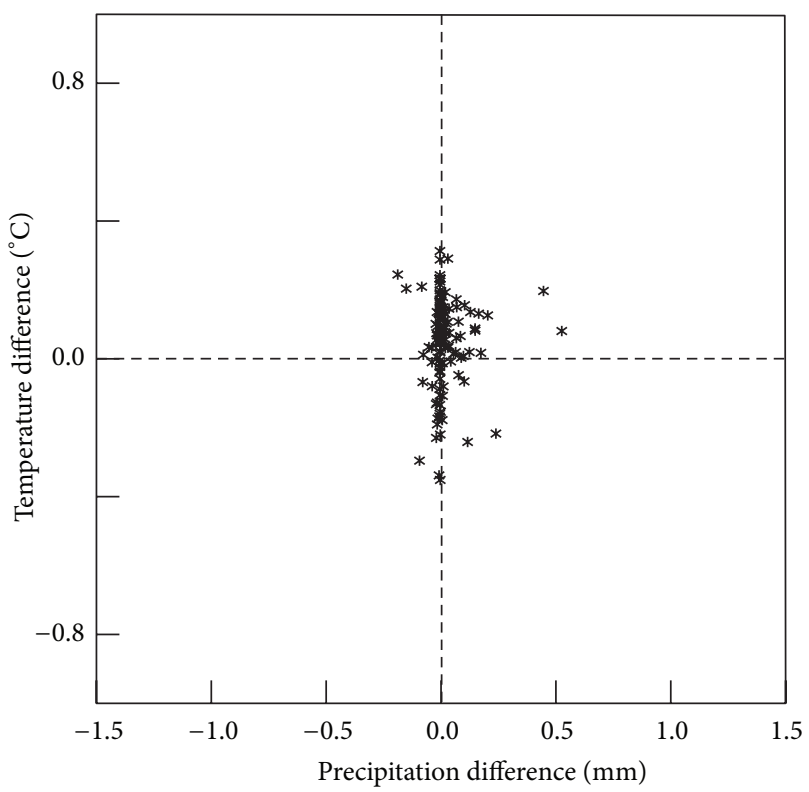

(d)

FIGURE 8: Precipitation difference and temperature difference at 4 different time periods ((a) 02-08 BT; (b) 08-14 BT; (c) 14-20 BT; (d) 2002 BT) from July to October 2010 between S-lake and S-nolake experiments.

Increased precipitation mainly consisted of convective precipitation from July to October (Figure 7). During the period, $55 \%, 32 \%$, and $16 \%$ of increased precipitation happen from 02-08 BT (Beijing Time), from 08-14 BT, and from 2002 BT, respectively. From $14-20$ BT, lakes reduce $3 \%$ precipitation.

Increased precipitation generally corresponds to warmer LSST in S-lake (Figure 8) from July to October, especially from $02-14$ BT. Owing to the big heat capacity of the water, lake is warmer than the land at nighttime and in the morning. Lake warming effect at $08 \mathrm{BT}$ averaged from July to October can reach to $2^{\circ} \mathrm{C}$ (Figure 9(a)) and can influence the lake area and the downwind land area about 514 grids in the model domain (with more than $0.05^{\circ} \mathrm{C}$ difference in the two simulations), much bigger than 48 lake grids.

Dynamically, the lake warming effect at night and in the morning induces breeze of the order of $1 \mathrm{~m} / \mathrm{s}$ from land to lake (Figure 9(a)). The low level horizontal convergence triggers 


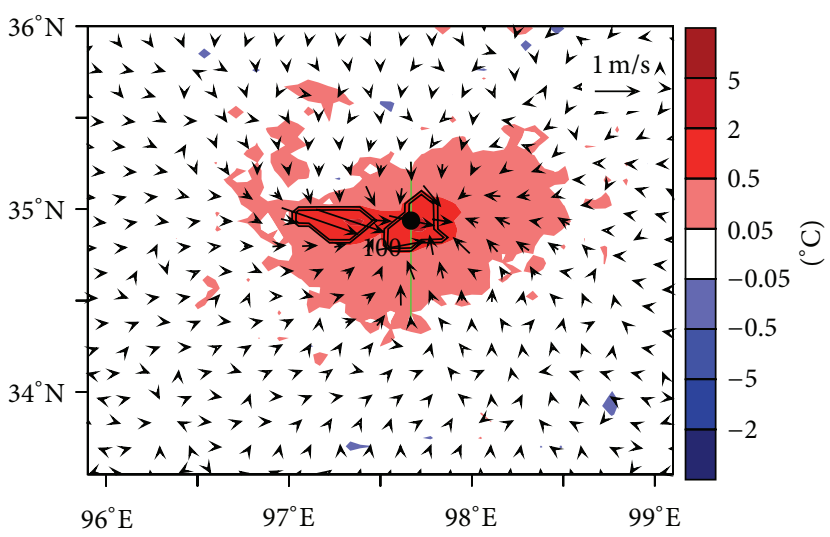

(a)

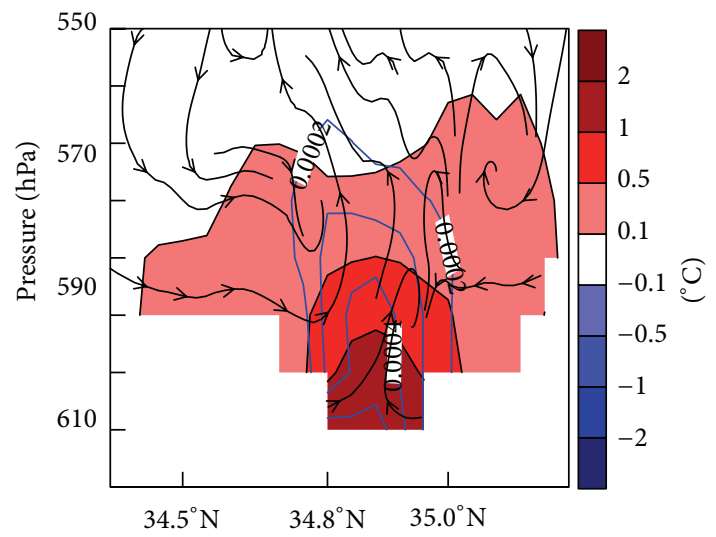

(b)

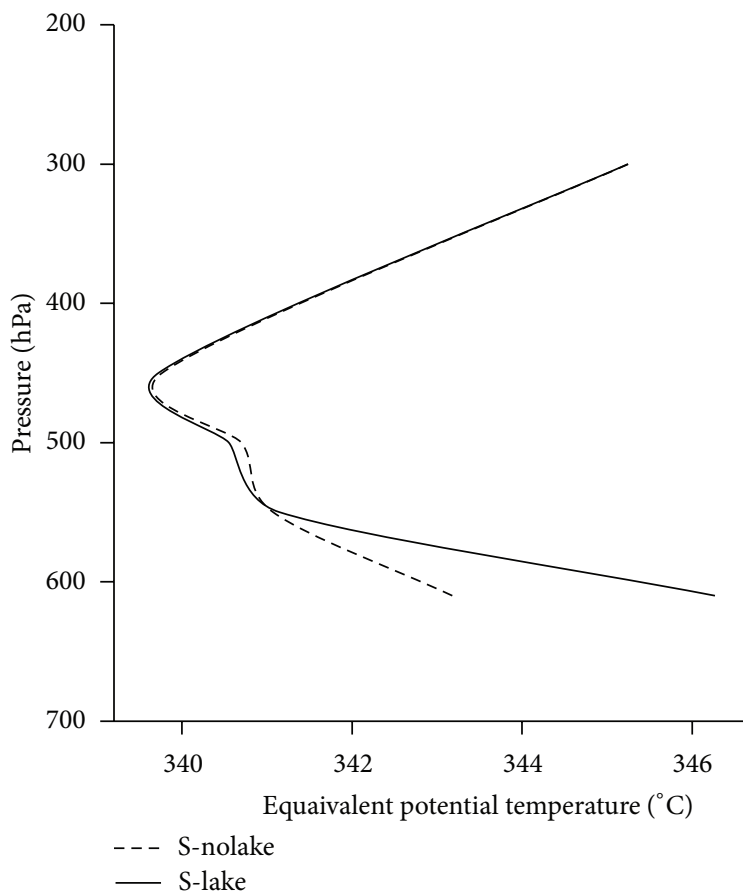

(c)

FIGURE 9: Difference of air temperature (shade), latent heat flux (contour), and wind (vector) between S-lake and S-nolake experiments at $08 \mathrm{BT}$ averaged from July to October 2010 (a); vertical plot of difference of temperature (shade), specific humidity (contour), and wind (streamline) between S-lake and S-nolake experiments along the green line in Figure 9(a) at 08 BT averaged from July to October 2010 (b); the profiles of equivalent potential temperature at the black dot in Figure 9(a) in S-lake and S-nolake experiments at 08 BT averaged from July to October 2010 (c).

the updraft to $540 \mathrm{hPa}$ (Figure 9(b)). Correspondingly, the high level divergent flow appears over the lake area and downdraft appears at the two sides of the updraft. Thus the secondary circulation forms and the low level energy and moisture are transported to the high level.

Thermally, lakes release more latent heat flux (Figure 9(a)) and evaporate more vapor to benefit the development of the convection for precipitation. The warm lake surface increases the instability of atmospheric profile (Figure 9(c)) and induces more precipitation in S-lake.

\section{Discussion and Conclusions}

In this study, impacts of Ngoring Lake and Gyaring Lake on local climate in the Yellow River source region in the Tibetan Plateau are investigated and qualified with the aid of the newly coupled WRF-CLM model that includes 10-layer lake scheme. For this purpose, two simulations are carried out with lake and without lake. The results show that WRF-CLM has good simulation capacity for both land and lake surface in the Yellow River source region and has better accuracy when including lakes. 
Although the lakes freeze from November to April (half year), overall warm lake effect is noticed. The lakes mostly reduce the maximum temperature all year round and increase the minimum temperature except in March. On a broad note, this phenomenon looks promising for proliferation of vegetation in the cold Tibetan Plateau.

In the study area, 94\% precipitation occurs from May to October and winter precipitation is negligible. Lakes increase up to $49 \%$ annual precipitation over the lake area and in the nearby region. The increase in precipitation as a result of lake effect is another contributing factor to support vegetation growth in the examined region. In addition to the impact on vegetation spread, the access water from increased precipitation and vegetation is projected to contribute for the irrigation requirement in the downstream area of the rivers originating from the Tibetan Plateau. Timely, lake effect always increases monthly precipitation except the cold period when the time slice is not the rainfall season and the precipitation is very small. $86 \%$ increased precipitation by lake effect happens from July to October. During the period, Ngoring Lake and Gyaring Lake result in up to $72 \%$ precipitation rise over lakes and the adjacent area. Increased precipitation mainly consisted of convective precipitation. $87 \%$ increased precipitation falls from $02-14 \mathrm{BT}$ and corresponds well with the warm lake surface temperature that increases the precipitation by thermal and dynamic forcing together. The warm lake surface induces the low level horizontal convergence and updraft over lake and provides energy and vapor to benefit the development of the convection for precipitation.

Although the lake effect on local climate has been investigated in the study, there are some limitations. (1) The study period is only one year and will be extended with the collection of longer time observation in future. (2) The analysis does not consider inundated areas and other wetland areas that are also present in the Tibetan Plateau during the rainy season and are predicted to have significant influence on the local climate as speculated from the wetland effect on Nile hydroclimatology. That will be considered in the model with the help of satellite data. (3) The other postulation is fixing of the lake depth as $17 \mathrm{~m}$, as in actual scenario the lake has an uneven depth. In future the gridded lake depth will be measured with a depth finder and put into the model for more actual numerical simulation.

\section{Conflict of Interests}

The authors declare that there is no conflict of interests regarding the publication of this paper.

\section{Acknowledgments}

The study was supported by the National Natural Science Foundation of China (41475011, 41130961, and 41275014) and APEC Climate Center. The authors acknowledge the support for using the computing resources at Supercomputing Center of Cold and Arid Regions Environmental and Engineering Research Institute, Chinese Academy of Sciences.

\section{References}

[1] V. Mishra, K. A. Cherkauer, L. C. Bowling, and M. Huber, "Lake Ice phenology of small lakes: impacts of climate variability in the Great Lakes region," Global and Planetary Change, vol. 76, no. 3-4, pp. 166-185, 2011.

[2] D. Lauwaet, N. P. M. van Lipzig, K. Van Weverberg, K. Ve Ridder, and C. Goyens, "The precipitation response to the desiccation of Lake Chad," Quarterly Journal of the Royal Meteorological Society, vol. 138, no. 664, pp. 707-719, 2012.

[3] M. Ricko, J. A. Carton, and C. Birkett, "Climatic effects on lake basins. Part I: modeling tropical lake levels," Journal of Climate, vol. 24, no. 12, pp. 2983-2999, 2011.

[4] P. Samuelsson, E. Kourzeneva, and D. Mironov, "The impact of lakes on the European climate as simulated by a regional climate model," Boreal Environment Research, vol. 15, no. 2, pp. 113-129, 2010.

[5] S. M. Steiger, R. Hamilton, J. Keeler, and R. E. Orville, "Lakeeffect thunderstorms in the lower great lakes," Journal of Applied Meteorology and Climatology, vol. 48, no. 5, pp. 889-902, 2009.

[6] M. D. MacKay, P. J. Neale, C. D. Arp et al., "Modeling lakes and reservoirs in the climate system," Limnology and Oceanography, vol. 54, no. 6, pp. 2315-2329, 2009.

[7] S. W. Hostetler, G. T. Bates, and F. Giorgi, "Interactive coupling of a lake thermal model with a regional climate model," Journal of Geophysical Research, vol. 98, no. 3, pp. 5045-5057, 1993.

[8] V. M. Stepanenko, S. Goyette, A. Martynov, M. Perroud, X. Fang, and D. Mironov, "First steps of a Lake Model intercomparison project: LakeMIP," Boreal Environment Research, vol. 15, no. 2, pp. 191-202, 2010.

[9] P. Verburg and J. P. Antenucci, "Persistent unstable atmospheric boundary layer enhances sensible and latent heat loss in a tropical great lake: Lake Tanganyika," Journal of Geophysical Research D: Atmospheres, vol. 115, no. 11, Article ID D11109, 2010.

[10] Z. Long, W. Perrie, J. Gyakum, D. Caya, and R. Laprise, "Northern lake impacts on local seasonal climate," Journal of Hydrometeorology, vol. 8, no. 4, pp. 881-896, 2007.

[11] J. D. Jacobs and L. D. Grondin, "The influence of an Arctic largelakes system on mesoclimate in south-central Baffin Island, Nwt, Canada," Arctic \& Alpine Research, vol. 20, no. 2, pp. 212219, 1988.

[12] D. A. R. Kristovich, G. S. Young, J. Verlinde et al., "The lakeinduced convection experiment and the snowband dynamics project," Bulletin of the American Meteorological Society, vol. 81, no. 3, pp. 519-542, 2000.

[13] T. A. Niziol, W. R. Snyder, and J. S. Waldstreicher, "Winter weather forecasting throughout the Eastern United States. Part IV: lake effect snow," Weather and Forecasting, vol. 10, no. 1, pp. 61-77, 1995.

[14] P. J. Sousounis and J. M. Fritsch, "Lake-aggregate mesoscale disturbances. Part II: a case study of the effects on regional and synoptic-scale weather systems," Bulletin of the American Meteorological Society, vol. 75, no. 10, pp. 1793-1811, 1994.

[15] R. W. Scott and F. A. Huff, "Impacts of the Great Lakes on regional climate conditions," Journal of Great Lakes Research, vol. 22, no. 4, pp. 845-863, 1996.

[16] K. Eerola, L. Rontu, E. Kourzeneva, and E. Shcherbak, "A study on effects of lake temperature and ice cover in HIRLAM," Boreal Environment Research, vol. 15, no. 2, pp. 130-142, 2010. 
[17] L. C. Bowling, D. L. Kane, R. E. Gieck, L. D. Hinzman, and D. P. Lettenmaier, "The role of surface storage in a low-gradient Arctic watershed," Water Resources Research, vol. 39, no. 4, 2003.

[18] S. W. Hostetler and P. J. Bartlein, "Simulation of lake evaporation with application to modeling lake level variations of HarneyMalheur Lake, Oregon," Water Resources Research, vol. 26, no. 10, pp. 2603-2612, 1990.

[19] E. E. Small, L. C. Sloan, S. Hostetler, and F. Giorgi, "Simulating the water balance of the Aral Sea with a coupled regional climate-lake model," Journal of Geophysical Research D: Atmospheres, vol. 104, no. 6, pp. 6583-6602, 1999.

[20] J. Jiang and Q. Huang, "Distribution and variation of lakes in Tibetan Plateau and their comparison with lakes in other part of China," Water Resources Protection, vol. 4, no. 6, pp. 24-27, 2004 (Chinese).

[21] W.-S. Li, L. Feng, and S.-L. Sun, "Influence of Zaling and Eling Lake on the annual discharge of the Huanghe River source area," Acta Geographica Sinica, vol. 56, no. 1, pp. 82-90, 2001 (Chinese).

[22] M. Li, Y. Ma, Z. Hu, H. Ishikawa, and Y. Oku, "Snow distribution over the Namco lake area of the Tibetan Plateau," Hydrology and Earth System Sciences, vol. 13, no. 11, pp. 2023-2030, 2009.

[23] Z. M. Subin, W. J. Riley, J. Jin, D. S. Christianson, M. S. Torn, and L. M. Kueppers, "Ecosystem feedbacks to climate change in California: development, testing, and analysis using a coupled regional atmosphere and land surface model (WRF3-CLM3.5)," Earth Interactions, vol. 15, no. 15, pp. 1-38, 2011.

[24] J. S. Kain, "The Kain-Fritsch convective parameterization: an update," Journal of Applied Meteorology, vol. 43, no. 1, pp. 170181, 2004.

[25] E. J. Mlawer, S. J. Taubman, P. D. Brown, M. J. Iacono, and S. A. Clough, "Radiative transfer for inhomogeneous atmospheres: RRTM, a validated correlated-k model for the longwave," Journal of Geophysical Research: Atmospheres, vol. 102, no. D14, pp. 16663-16682, 1997.

[26] K. W. Oleson, G. Y. Niu, Z. L. Yang et al., "Improvements to the community land model and their impact on the hydrological cycle," Journal of Geophysical Research G: Biogeosciences, vol. 113, no. 1, Article ID G01021, 2008.

[27] Y. Noh, W. G. Cheon, S. Y. Hong, and S. Raasch, "Improvement of the K-profile model for the planetary boundary layer based on large eddy simulation data," Boundary-Layer Meteorology, vol. 107, no. 2, pp. 401-427, 2003.

[28] P. K. Hope, N. Nicholls, and J. L. McGregor, "The rainfall response to permanent inland water in Australia," Australian Meteorological Magazine, vol. 53, no. 4, pp. 251-262, 2004.

[29] L. Zhao, J. Jin, S. Y. Wang, and M. B. Ek, "Integration of remotesensing data with WRF to improve lake-effect precipitation simulations over the Great Lakes region," Journal of Geophysical Research D: Atmospheres, vol. 117, no. 9, 2012.

[30] K. W. Oleson, Y. G. Dai, M. Bonan et al., “Technical description of the Community Land Model," 2004, http://www.cgd.ucar .edu/tss/clm/distribution/clm3.0/index.html.

[31] M. Kanamitsu, W. Ebisuzaki, J. Woollen et al., "NCEP-DOE AMIP-II reanalysis (R-2)," Bulletin of the American Meteorological Society, vol. 83, no. 11, pp. 1631-1559, 2002.

[32] H. Morrison, J. A. Curry, and V. I. Khvorostyanov, "A new double-moment microphysics parameterization for application in cloud and climate models. Part I. Description," Journal of the Atmospheric Sciences, vol. 62, no. 6, pp. 1665-1677, 2005.
[33] J. Dudhia, "Numerical study of convection observed during the Winter Monsoon experiment using a mesoscale twodimensional model," Journal of the Atmospheric Sciences, vol. 46, no. 20, pp. 3077-3107, 1989.

[34] K. N. Yeager, W. J. Steenburgh, and T. I. Alcott, "Contributions of lake-effect periods to the cool-season hydroclimate of the great salt lake Basin," Journal of Applied Meteorology and Climatology, vol. 52, no. 2, pp. 341-362, 2013. 

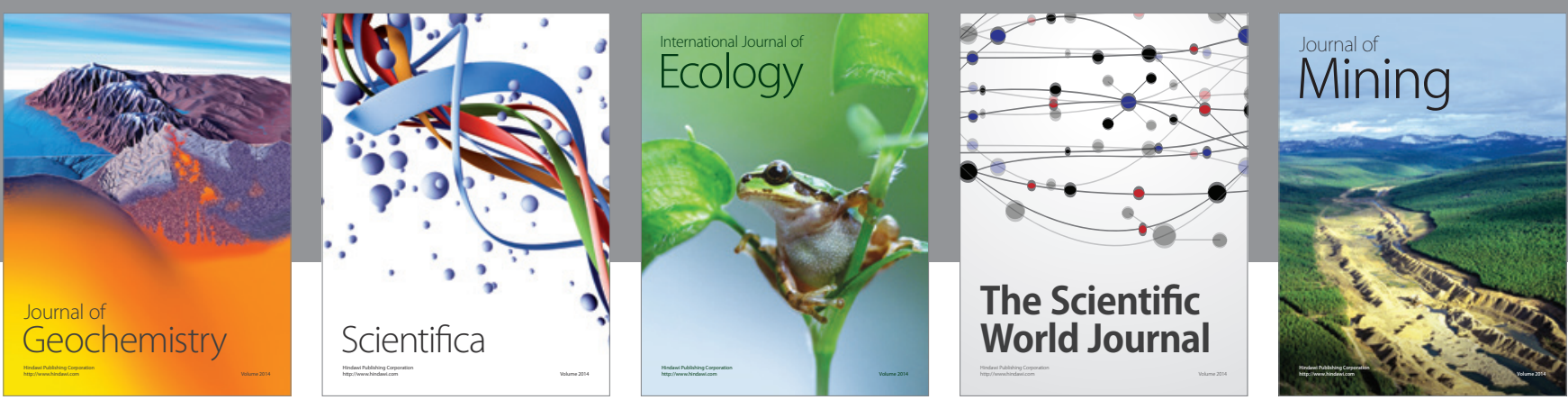

The Scientific World Journal
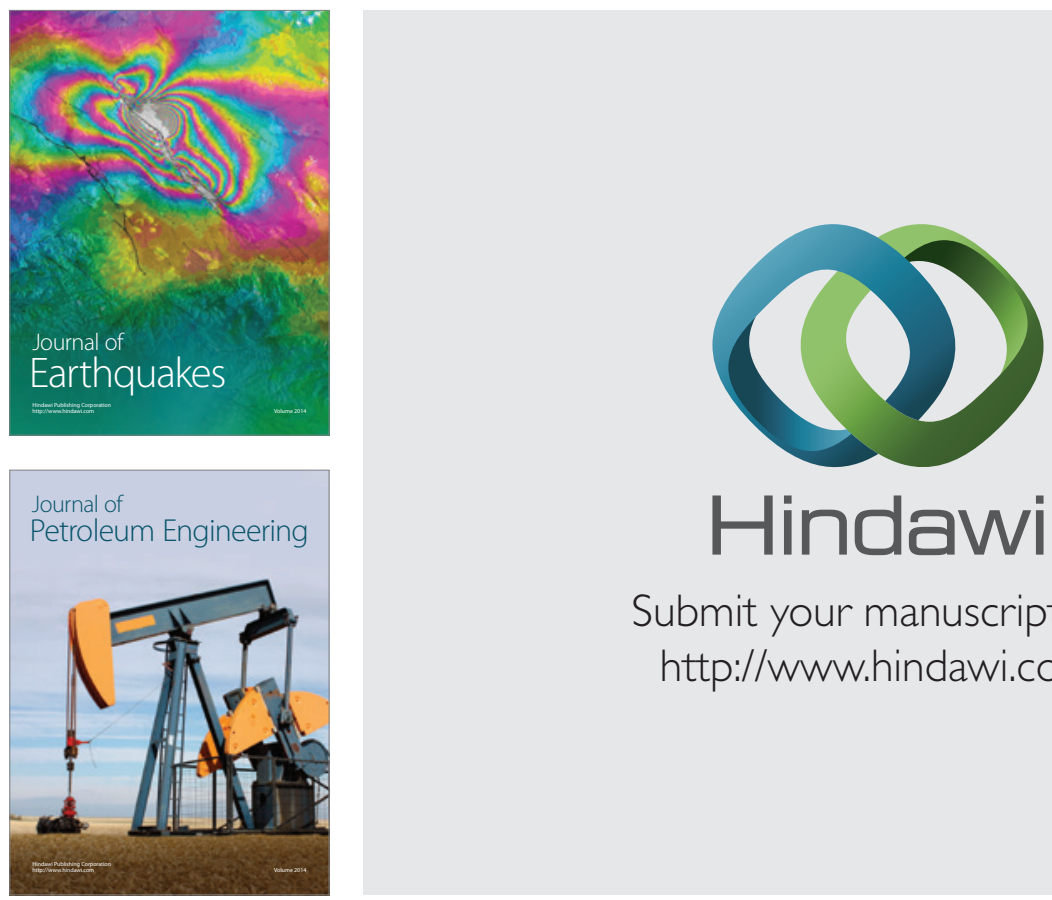

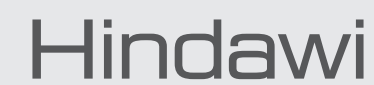

Submit your manuscripts at

http://www.hindawi.com
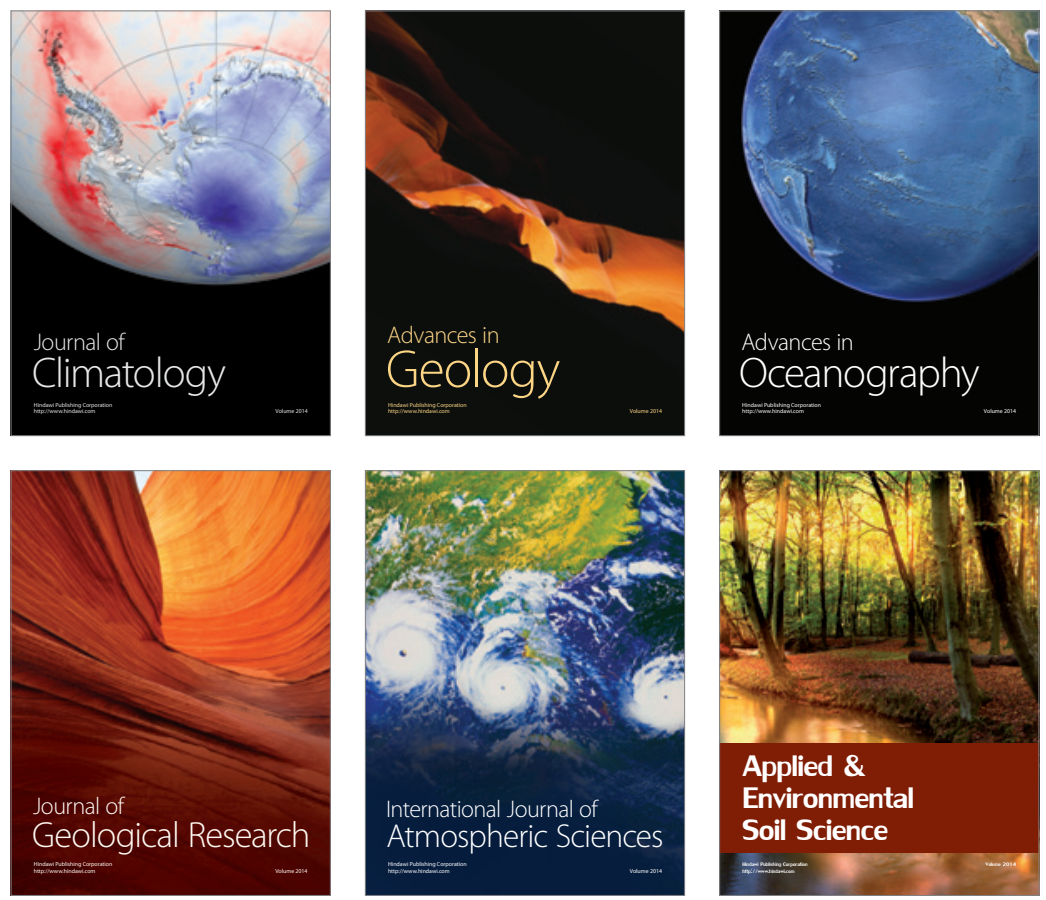
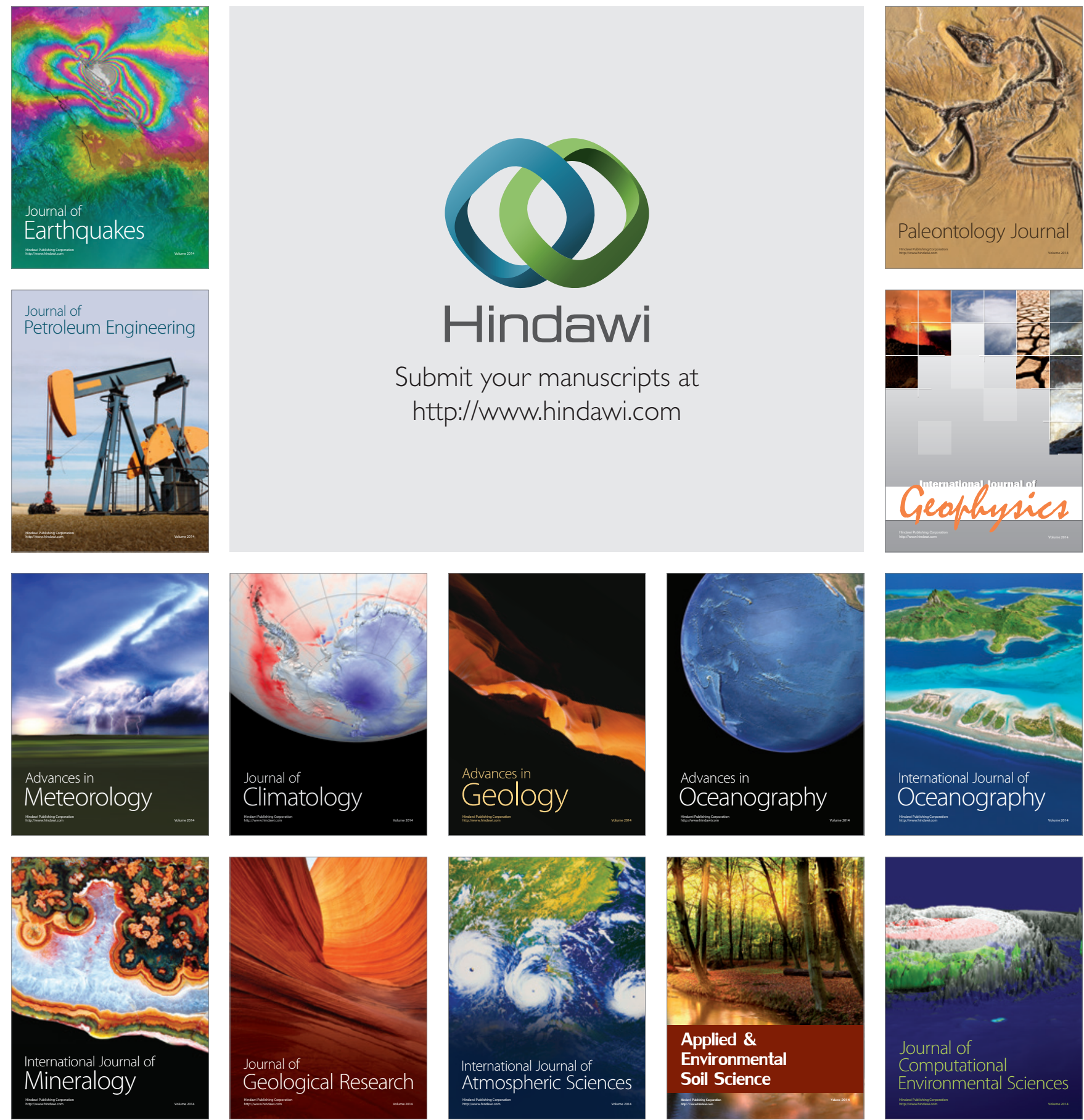